\title{
ESTÁGIO COM GINÁSTICA LABORAL: RELATO DE EXPERIÊNCIA
}

\section{RELATO DE EXPERIÊNCIA}

FLORES, Fábio Fernandes ${ }^{1}$

COTRIM, Daiane Maria de Jesus ${ }^{2}$

ANDRADE, Daniela da Silva ${ }^{3}$

SOUZA, Luiz Humberto Rodrigues ${ }^{4}$

FLORES, Fábio Fernandes. Et al. Estágio com Ginástica Laboral: relato de experiência. Revista Científica Multidisciplinar Núcleo do Conhecimento. Ano 04, Ed. 09, Vol. 05, pp. 54-67. Setembro de 2019. ISSN: 2448-0959, Link de acesso: https://www.nucleodoconhecimento.com.br/educacao-fisica/ginastica-laboral

\section{RESUMO}

O estágio é configurado como uma das etapas da formação, para tanto é imprescindível que o corpo discente tenha saberes que sustentem suas ações nos campos de atuação do curso. Deste modo o exercício da profissão se faz necessário para que 0 acadêmico possa ter maiores condições de êxito quando estiver em atividade laboral. O presente trabalho tem por objetivo descrever a vivência do Estágio VI, apontando as facetas da atuação com Ginástica Laboral (GL). Esta experiência se

\footnotetext{
${ }^{1}$ Especialista em Atividade Física, Saúde e Sociedade (UNEB - 2016), Especialista em Educação Física Escolar (FUNORTE - 2011), Graduação em Educação Física (UNEB - 2009).

2 Especialista em Gestão Pública (FASG - 2018) e Graduação em Educação Física (UNEB - 2015).

${ }^{3}$ Graduação em Educação Física (UNEB - 2015).

${ }^{4}$ Doutor em Educação Física (UCB - 2019), Mestre em Educação Física (UCB - 2007)

e Graduação em Educação Física (UFU - 2004).
} 
deu a partir do projeto de intervenção desenvolvido na UNEB com os funcionários dos diferentes setores da instituição. O trabalho tem abordagem qualitativa, com caráter descritivo e no formato de relato de experiência. A GL ocorria prioritariamente em seus setores, sendo usado a GL Preparatória e GL compensatória, ambas com duração de 30 minutos. Para coleta dos dados foi usado um roteiro de observação, o diário de bordo e levantamento de informações (similar a anamnese). A avaliação das intervenções ocorreu por meio da roda de conversa. A estrutura física dos setores tinha diferentes dimensões espaciais e espaço de movimentação, mas com ar condicionado e no mínimo: uma mesa ou balcão, duas cadeiras, um computador, um armário. O fato de o estágio ter ocorrido na própria instituição foi possível usar mecanismos distintos para o cumprimento do objetivo. Os participantes fizeram queixas de ordem física e psicológica. Dentre os resultados da intervenção destacase a redução das dores, mais disposição e reconhecimento da importância da atividade física. As críticas dos participantes foram à transferência da GL para o final do expediente e aumento da duração da GL. A intervenção do estágio teve importância tripla: na vertente acadêmica, pois contribuiu para que tivéssemos uma experiência formativa com um campo de trabalho; na vertente institucional, por apresentar um cenário talvez desconhecido e ainda revelar uma possibilidade de cuidado para com o funcionário; na vertente dos funcionários, pelo fato de ter oportunizado momentos de redução dos impactos da sobrecarga do trabalho com a GL e ainda o entendimento do quão é necessário ter um estilo de vida saudável.

Palavras-chaves: Estágio, educação física, ginástica, saúde do trabalhador.

\section{INTRODUÇÃO}

O estágio é configurado como uma das etapas da formação, para tanto se faz necessário que o corpo discente tenha saberes que sustentem suas ações nos campos de atuação do curso. Tendo em vista a articulação da base teóricometodológica no futuro local laboral (PIMENTA; LIMA, 2011), este processo proporciona a oportunidade de demonstrar os conhecimentos obtidos na graduação e treinar suas competências apenas a partir da segunda metade do curso (JONAS et al. 2011). 
Esta etapa deve ser entendida como momento de aquisição de conhecimentos, sendo imprescindível a valorização das várias esferas: estrutura curricular do curso, profissionais envolvidos e corpo discente (RAMOS, 2002). Aspectos como segurança no local do estágio, ética e consistência teórica tem uma contribuição positiva na formação profissional.

O professor de estágio deve conhecer o panorama das turmas antes de cada discente iniciar a intervenção e ainda ampliar os horizontes de modo que seja debatido as nuances do ser profissional. Tal afirmativa decorre do fato dos recém-formados terem medo do novo, à sensação de não estar preparado para enfrentar o mercado de trabalho e ainda apontar como dificuldade de inserção em algum trabalho a falta de experiência (JONAS et al. 2011).

De maneira crítica Pimenta e Lima (2011) indicam que a aproximação à realidade só tem sentido quando tem conotação de envolvimento, de intencionalidade, pois a maioria dos estágios burocratizados, carregados de ficha de observação, é míope, o que aponta para a necessidade de um aprofundamento conceitual do estágio e das atividades que nele se realizam.

Neste processo é possível também o desenvolvimento do pensamento crítico-criativo, haja vista o exercício da visão crítica acerca da intervenção laboral, isto mediante ao incentivo de exposição (relatos) da análise (sugestões, pontos negativos e positivos) do que fora observado e realizado pelo corpo discente (SILVA, 2003).

De forma preocupante e que implica no processo de amadurecimento discente, Jonas et al. (2011) citam que se exige do estagiário a realização de funções próprias dos profissionais formados e situações onde discentes não tiveram acompanhamento de profissional formado no local de estágio; tais aspectos podem ser um dos indicativos que revela no estudo o estágio como processo sem contribuição para a atuação profissional de alguns estudantes. Deve-se destacar que o acadêmico está em processo de aprendizagem, sendo assim, é prudente que tenha incumbências conforme seu nível de formação e auxílio dos profissionais envolvidos no processo (professor da instituição e profissional que trabalha no local do estágio). 
Portanto, o exercício da profissão se faz preponderante para que o acadêmico possa ter maiores condições de êxito quando estiver em atividade laboral. Deste modo, o estágio curricular é imprescindível para que o corpo discente possa aprender mais acerca da intervenção profissional (VASCONCELOS, 2010).

A Universidade do Estado da Bahia (UNEB) - Campus XII possibilita a seu corpo discente (Educação Física) a liberdade de escolher o campo de estágio de acordo com os seus interesses, conforme o Regulamento de Estágio. Sendo assim, optou-se em intervir com Ginástica Laboral (GL). A razão pela escolha decorre de uma prévia observação de fatos e relatos dos funcionários desta instituição sobre incômodos posturais causados diariamente pelos esforços e desgastes no trabalho, sobretudo nos punhos, pescoço, ombros e lombar, bem como cansaço mental, o estresse, e físico.

A GL é compreendida como o conjunto de atitudes com o intento no enfrentamento dos distúrbios físicos e emocionais tratando-se da saúde do trabalhador; além da prevenção de lesões e auxiliar na reabilitação (SOARES; ASSUNÇÃO; LIMA, 2006). De forma aditiva, Oliveira (2006) menciona que atua de forma terapêtica e na prevenção de doenças ocupacionais como as Lesões por Esforço Repetitivo (LER) e os Distúrbios Osteomusculares Relacionados com o Trabalho (DORT). A mesma é dividida em três tipos: a preparatória, realizada antes da jornada de trabalho; a compensatória, realizada durante a jornada; e de relaxamento, efetuada ao final do expediente (FIGUEIREDO; MONT'ALVÃO, 2005).

Cabe apontar que esta ação não é restrita a área da Educação Física, podendo a Fisioterapia também usar esta intervenção. Ambos têm habilitação para realização da GL, devendo ter capacitação e estar legalmente cadastrados nos respectivos Conselhos profissionais, mas o diferencial entre as duas é que no primeiro curso há na formação elementos das atividades lúdicas, criativas e em grupos, já no segundo curso, aprofundamento dos conhecimentos de fisiologia (MORAES; SILVA, 2016).

O presente trabalho tem por objetivo descrever a vivencia do Estágio VI apontando as facetas da atuação com GL. Esta experiência se deu a partir do projeto de intervenção 
desenvolvido na UNEB com os funcionários dos diferentes setores da instituição, que teve duração de nove semanas.

\section{METODOLOGIA}

Este trabalho tem abordagem qualitativa e caráter descritivo. O mesmo é um relato de experiência, "uma ferramenta de pesquisa descritiva que apresenta uma reflexão sobre uma ação ou um conjunto de ações que abordam uma situação vivenciada no âmbito profissional de interesse da comunidade científica" (CAVALCANTE; LIMA, 2012, p.96). De acordo com Lakatos e Marconi (2011) na pesquisa descritiva, trata-se de um olhar qualitativo que aborda a problemática delineada a partir de métodos descritivos e observacionais, descrevendo aspectos mais profundos.

A intervenção aconteceu na UNEB com oito setores: Secretaria Acadêmica, Financeiro, Protocolo, Colegiados (Educação Física, Pedagogia, Enfermagem e Administração), Biblioteca, Informática, Telefonistas e o Núcleo de Pesquisa, Ensino e Extensão (NUPEX); tendo uma totalidade de 26 funcionários como participantes (8 homens e 18 mulheres). Os dias desta atividade foram nas segundas-feiras, quartasfeiras e quintas-feiras no turno matutino, perfazendo a carga horária semanal de 4 horas e 30 minutos.

O planejamento e cronograma das atividades tiveram similaridade com o que fora realizado por Vasconcelos (2010). Deste modo, quanto ao primeiro teve-se como premissa as exigências físicas laborais. Em relação ao segundo, a organização da GL compreendia de: atividades dinâmicas como aquecimento muscular e articular (geralmente uma brincadeira), alongamento (das estruturas mais utilizadas durante a jornada de trabalho), momento explicativo (assuntos distintos, porém relacionados com estilo de vida positivo) e/ou relaxamento. A GL ocorria prioritariamente em seus setores, sendo usado a GL Preparatória (predominante) e GL compensatória, ambas com duração de 30 minutos. A duração foi análoga a intervenção de Santos et al. (2007), no entanto com organização e tempo das etapas divergentes. 
Para coleta dos dados foi usado um roteiro de observação (SILVA, 2003): descrição da estrutura física mais o seu entorno (acessórios/itens extras) e ainda verificação da possibilidade de mecanismos distintos para alcançar o objetivo proposto; e também o diário de bordo para registrar as informações da vivência. Acerca do mesmo, Cañete (2010) o considera uma escrita muito reflexiva que ultrapassa a escrita burocrática; indica ainda que este instrumento tem a intenção de registrar a prática pedagógica do professor e possibilita (re)pensá-la, deste modo essa escrita pode permitir que o professor se configure como produtor de conhecimentos sobre a prática. De forma complementar, Alves (2004, p.224) aponta que:

O diário pode ser considerado como um registro de experiências pessoais e observações passadas, em que o sujeito que escreve inclui interpretações, opiniões, sentimentos e pensamentos, sob uma forma espontânea de escrita, com a intenção usual de falar de si mesmo.

Para avaliar as aulas foi usada à roda de conversa, que prioriza discussões em torno de uma temática (relacionado com estilo de vida e saúde) e, no processo dialógico, as pessoas podem apresentar suas elaborações, mesmo contraditórias, sendo que cada pessoa instiga a outra a falar, sendo possível se posicionar e ouvir o posicionamento do outro (MÉLLO et al. 2007). Deste modo, os usuários possuem a liberdade de contar suas histórias do cotidiano e relatar sobre as intervenções efetivadas, quais os anseios e expectativas, buscando compreendê-los por meio do exercício de pensar compartilhado, o qual possibilita a significação dos acontecimentos.

No primeiro dia do estágio foi realizado um levantamento de informações, similar a anamnese, sobre a rotina de trabalho, funções desempenhadas, principais queixas e presença de dores; em seguida foi explicitado acerca da GL.

No decorrer do estágio eram realizadas variações quanto ao posicionamento corporal, mudanças de movimento e organização das pessoas nas atividades (individual, dupla ou grupo). Os recursos materiais usados foram balões, bolas, colchonetes, tensor elástico, aparelho de som e cadeiras, sendo utilizados de maneira alternada, ou seja, os itens não eram repetidos em dois dias seguidos. 


\section{RESULTADOS E DISCUSSÃO}

A estrutura física dos setores tinha diferentes características: local pequeno com espaço muito reduzido para movimentação (Protocolo, Colegiados, Telefonistas e NUPEX), local pequeno com pouco espaço para movimentação (Financeiro e Informática), local médio com espaço para movimentação (Secretaria Acadêmica e Biblioteca). Quanto ao mobiliário, todos os ambientes tinham ar condicionado e no mínimo: uma mesa ou balcão, duas cadeiras, um computador, um armário. Diante disso, os locais para a realização da GL foram: local pequeno com pouco espaço movimentação, local médio com espaço para movimentação e sala de espera (espaço aberto, coberto, arejado e com piso).

Pelo fato de o estágio ter ocorrido na própria instituição foi possível usar mecanismos distintos para o cumprimento do objetivo, pois na mesma tem a sala de materiais pedagógicos, deste modo à logística quanto à utilização de recursos diversos auxiliou muito na execução do planejamento.

Os dados referentes à observação e informações colhidas no primeiro dia foram: dores musculares generalizadas, cansaço, desconforto na postura, rotina estressante, predominância de uso das articulações da coluna (sobretudo a cervical), punho e quadril.

No sentido de propor uma sociabilidade maior, houve junção de setores devido o número pequeno de participantes, Biblioteca com a Secretaria Acadêmica e Telefonista com o Financeiro, deste modo em cada atividade da GL havia entre cinco a sete funcionários.

No decorrer do estágio foi usado o diário de bordo e rodas de conversa (no final da atividade). Com o primeiro registrou-se queixas importantes, principalmente relacionados com o estresse aumentado, algia e desconfortos.

Um funcionário do setor da biblioteca relatou que além do cansaço (físico e mental) sentia alguns incômodos relacionados a movimentos repetitivos ao utilizar o 
computador, bem como dores no corpo pelo tempo que trabalhava sentado. De forma análoga, uma participante do setor da Secretaria Acadêmica disse sobre seu esgotamento (físico e mental) no fim do expediente e da sensação de muitas dores no corpo todo, sobretudo no pescoço, punho e lombar, ocasionadas pelo trabalho.

O estudo de revisão de Serra, Pimenta e Quemelo (2014) sobre saúde do trabalhador indica que a ginástica laboral pode ser uma forma potencial de intervenção para reduzir os problemas de saúde no ambiente de trabalho. Além disso, a inclusão da atividade física regular no trabalho aumenta a motivação, satisfação (pessoal e social) e condição física necessária para o desenvolvimento das atividades laborais com mais produtividade (eficiência, eficácia e efetividade) (LISBOA; NOGUEIRA; SÁ, 2016). Tendo em vista a promoção da saúde do trabalhador, tais informações ratificam a importância da GL no ambiente de trabalho.

A mesma funcionária da Secretaria Acadêmica, afirmou que com GL notou que havia amenizado os incômodos. Na ocasião ainda nos direcionou a proposição de que a GL deveria acontecer todos os dias, pois ela sentia essa necessidade diária e não apenas duas ou três vezes na semana. O caso descrito destaca o quão importante é a atividade. Embora tenha sugerido mais dias na semana, isso não era possível, pois a GL deveria ocorrer somente nos dias designados para o estágio.

Durante a intervenção os participantes do estágio interagiam constantemente com os demais presentes, principalmente com as dinâmicas. De forma ampliada e sobre a sociabilidade, Vasconcelos (2010) aponta que os relatos dos participantes que participaram da GL foram: sensação de mais disposição para a jornada de trabalho, mais interação do grupo, melhora na postura e qualidade de vida; e Militão (2001) descreve que com a GL o grupo ficou mais unido, que houve uma melhora do relacionamento, uma sensação de bem-estar e melhora do ânimo, gerando assim maior disposição. Deste modo, as referências supracitadas ratificam o aspecto social como dimensão de impacto positivo no cotidiano laboral.

O relaxamento foi à atividade de maior apreço, uma hipótese para este panorama pode ser por causa da pausa associada com o posicionamento corporal (decúbito 
dorsal sobre o colchonete) e execução de movimentos suaves com música a caráter. Este momento tinha duração pequena, não podendo prolongar em consequência do cumprimento da realização da GL em outros setores.

No decorrer do estágio houve duas sugestões. Uma funcionária do setor Nupex ao término do relaxamento relatou que este momento deveria ser feito no fim do expediente, pois, é quando estão mais cansados, no entanto não era possível devido ao horário destinado para o estágio (sempre pela manhã).

Além desta, várias pessoas pediram para aumentar o tempo, pois consideravam pouco demais, sugestão também realizada pelos participantes do trabalho de Vasconcelos (2010), que solicitavam a mudança de 15 para 30 minutos; todavia, no nosso caso era inviável em decorrência da indisponibilidade temporal.

A roda de conversa ocorria sempre ao final das atividades de GL. Um momento para falar sobre a atividade e realizar críticas. A respeito da opinião do grupo quanto a $G L$, diziam que gostavam muito dos momentos interativos (como as brincadeiras) que visavam trabalho em equipe, respeito ao próximo, autoestima, pois auxiliavam nos aspectos físicos e psicológicos. Este cenário positivo converge com o ambiente encontrado ao ministrar a GL, pois respondiam muito bem as atividades propostas, sempre apresentavam disposição e bastante satisfação ao participar.

Em cada encontro sempre era ressaltado um quesito relacionado com estilo de vida positivo (NAHAS, 2017), tais como: a maneira ideal da respiração, o porquê da GL, cooperação, respeito ao próximo, interação entre o grupo, estresse e importância da atividade física/exercício físico.

Quanto à respiração, no sentido de que houvesse a compreensão da maneira correta (diafragmática) orientamos que deitassem nos colchonetes e fizessem o exercício da respiração com a mão sobre o abdômen, onde na inspiração (pelo nariz) haveria a elevação do abdômen e na expiração (pela boca) redução do abdômen. O objetivo era aprofundar e diminuir o ciclo respiratório, que pode estar sofrendo influências do neurohormônios do estresse e da ansiedade, esta prática resulta em um padrão 
respiratório lento, profundo, regular e sem esforço; e isso implica numa contribuição da redução do estresse (NEVES NETO, 2011). A atividade teve grande importância, pois mencionaram entender melhor o processo da respiração e que passariam a tentar usar isso no cotidiano.

Em relação à prática regular de atividade física, embora não tenhamos relatos que alguém tenha iniciado alguma (caminhada, ciclismo ou outra), houve o reconhecimento de sua importância em detrimento do quadro que se apresentavam (queixas de cansaço, indisposição, massa corporal elevada e estresse elevado). Deste modo, a GL sensibilizou o grupo para uma mudança no estilo de vida. Cenário diferente do encontrado no estudo de Militão (2001), já que além dos participantes ficarem mais motivados a fazer exercício, 37\% tiveram mudanças no lazer, passando estes a caminhar e praticar esportes nos finais de semana.

Cabe destacar que nossa ação no estágio teve consonância com Vasconcelos (2010), pois durante e após a realização das aulas, foram realizados diálogos, com o objetivo de visualizar a satisfação dos participantes bem como incentivá-lo a corrigir as falhas que estariam no momento executando (feedback), utilizando isso como referência para um aprimoramento maior da prática.

$\mathrm{Na}$ última semana de estágio, foi realizado uma culminância com os participantes. Neste momento explicamos e detalhamos o que fora executado e ainda agradecemos pela colaboração. Diante da interação e assiduidade premiamos o setor da Acadêmica de forma simbólica (bombons). Os participantes expressaram sentimento de muita gratidão, falaram que iria fazer muita falta as manhãs de atividades e ressaltaram mais uma vez a importância de uma implantação de um projeto permanente de GL no Campus XII.

Um dado importante refere-se à ausência de um componente específico no currículo de Educação Física da UNEB sobre GL, uma realidade também na Universidade Estadual da Paraíba (LIMA, 2016). Tal panorama compromete o processo de aprendizagem, tendo em vista as complexidades para aprofundamento de estudos da temática e ainda do contato com professor para debater questões peculiares. No 
entanto, a intervenção com a GL somada aos estudos contribui de maneira ímpar na aquisição de conhecimento, complementando o currículo carente do tema (LOPES FILHO et al., 2014).

Após o término da intervenção ocorreu o Seminário de Estágio, momento no qual acontece a apresentação do corpo discente das propostas de trabalho (intervenções diversas), as conquistas, as dificuldades, avaliações do processo e proposições. Isso na presença do corpo docente da instituição, dos profissionais dos locais de estágio e das turmas de Educação Física. Tal evento tem a premissa de discutir e refletir sobre o processo de formação, algo que Almeida e Moreira (2012) sugerem em seu estudo e que é realidade na UNEB - Campus XII. Este momento específico é edificante, pois a discussão em torno do que é explanado contribui no desenvolvimento formativo do corpo discente, tanto dos que estão em estágio, quanto dos que ainda não estão neste momento.

\section{CONSIDERAÇÕES FINAIS}

As instituições devem reconhecer a importância dos funcionários, quer seja na privada, quer seja na pública, sendo necessário o cuidado para com a saúde no sentido de tratar as pessoas com mais humanidade. Cabe destacar que quando medidas são tomadas com tal propósito, a exemplo da GL, há uma contribuição para um melhor empenho laboral.

Anterior ao início do estágio as pessoas que trabalhavam na instituição já indicavam os sinais dos impactos da jornada de trabalho, pois citaram queixas de ordem física e psicológica. Este prisma demonstra o grau de comprometimento na saúde.

O roteiro de observação possibilitou a constatação que os ambientes de desenvolvimento profissionais são estruturados e climatizados. E devido a sua dimensão ampliada e diversificada, bem como a existência da sala de materiais pedagógicos há a possibilidade de realização de ações distintas de promoção à saúde para com os trabalhadores da UNEB. 
Tanto pelo diário de bordo quanto nas rodas de conversa houve satisfação dos participantes com a GL. Baseado nas falas no decorrer a intervenção, o estágio contribuiu na sociabilidade interna e alívio de dores. Visualizar e ouvir estes aspectos mais a receptividade, relatos dos benefícios e pedidos de continuidade da GL potencializou o empenho para melhorar nossa ação (do planejamento a execução). Com isso, o estágio teve uma parcela expressiva de contribuição no desenvolvimento profissional, pelo fato de ter possibilitado uma experiência enriquecedora num campo de trabalho.

Não ter um profissional com experiência na GL como regente foi desafiador, tendo em vista que implicou em dificuldades maiores no processo. Pois tudo era novo, a alternativa foi buscar apoio em pesquisas e pessoas (discentes prestes a formar) para colaborar na aquisição de propriedade para executar a GL.

Seria importante uma atenção das instâncias administrativas da instituição em alguns quesitos. Ao colegiado caberia uma discussão para criar para os estudantes algum tipo de formação para contemplar a diversidade do campo de atuação, tendo em vista que no currículo formal inexiste GL. Com abrangência maior, a direção poderia debater com os cursos de Educação Física e Enfermagem (por serem da área da saúde) possibilidades de intervenção tendo como foco a atenção à saúde dos funcionários.

A intervenção do estágio teve importância tripla: na vertente acadêmica, pois contribuiu para que tivéssemos uma experiência formativa com um campo de trabalho; na vertente institucional, por apresentar um cenário talvez desconhecido e ainda revelar uma possibilidade de cuidado para com o funcionário; na vertente dos funcionários, pelo fato de ter oportunizado momentos de redução dos impactos da sobrecarga laboral e o entendimento do quão é necessário ter um estilo de vida saudável. 


\section{REFERÊNCIAS}

ALMEIDA, Francisca Franciely Veloso; MOREIRA, Evando Carlos. Contribuições da disciplina de estágio supervisionado de um curso de licenciatura em educação física: a percepção discente. Conexões: Educação Física, Esporte e Saúde, Campinas, v. 10, n. 2, p. 77-102, ago. 2012. Disponível em: <https://periodicos.sbu.unicamp.br/ojs/index.php/conexoes/article/view/8637676>. Acesso em: 14 fev. 2019.

ALVES, Francisco Cordeiro. Diário: um contributo para o desenvolvimento profissional dos professores e estudo dos seus dilemas. Millenium: Revista do ISPV (Instituto politécnico de Viseu), Viseu, n. 29, p. 222-239, dez. 2004. Disponível em: <http://www.ipv.pt/millenium/Millenium29/30.pdf>. Acesso em: 14 fev. 2019.

CAÑETE, Lílian Sipoli Carneiro. O diário de bordo como instrumento de reflexão crítica da prática do professor. 2010. 151f. Dissertação (Mestrado em Educação) Universidade Federal de Minas Gerais, Minas Gerais, 2010. Disponível em: <http://www.bibliotecadigital.ufmg.br/dspace/handle/1843/BUOS-8CSKSG>. Acesso em: 14 fev. 2019.

CAVALCANTE, Bruna Luana de Lima; LIMA, Uirassú Tupinambá Silva de. Relato de experiência de uma estudante de Enfermagem em um consultório especializado em tratamento de feridas. Journal of Nursing Health, Pelotas, v. 2, n. 1, p. 94-103, 2012. Disponível

em: $<$ https://periodicos.ufpel.edu.br/ojs2/index.php/enfermagem/article/view/3447/2832>. Acesso em: 14 fev. 2019.

FIGUEIREDO, Fabiana; MONT’ALVÃO Cláudia. Ginástica Laboral e Ergonomia. Rio de Janeiro: Sprint, 2005.

JONAS, Elaine Cristina; REDONDO, Francisca Cirnanda Fernandes Spim; NEVES, Nilson Alves das; FERNANDES, Rosemeire Gomes; SILVA, Sheila Aparecida Pereira dos Santos. Estágios na formação profissional e dificuldades percebidas por 
profissionais de educação física em seu primeiro ano de atuação. Revista Cocar, Belém, v. 5, n. 10, p. 95-107, jul./dez. 2011. Disponível em: $<$ https://paginas.uepa.br/seer/index.php/cocar/article/view/201>. Acesso em: 14 fev. 2019.

LAKATOS, Eva Maria, MARCONI, Marina de Andrade. Fundamentos de metodologia científica, $6^{\circ}$ ed. São Paulo: Atlas, 2011.

LIMA, Edilene Guedes de. Ginástica laboral para trabalhadores da indústria na cidade de Campina Grande (PB): uma experiência vivenciada. 2016. 25f. Trabalho de conclusão de curso (Graduação em Educação Física) - Centro de Ciências Biológicas e da Saúde, Universidade Estadual da Paraíba, Paraíba, 2016. Disponível em: <http://dspace.bc.uepb.edu.br/jspui/handle/123456789/9014>. Acesso em: 14 fev. 2019.

LISBÔA, Felipe Augusto Casé Porto; NOGUEIRA, Nayane Isabelly Oliveira; SÁ, Marcos Tulio de. Ginástica laboral e qualidade de vida do trabalhador: uma revisão de literatura. Revista Movimenta, Goiânia, v. 9, n. 3, p. 499-510, 2016. Disponível em: <http://www.revista.ueg.br/index.php/movimenta/article/view/3361>. Acesso em: 8 mar. 2019.

LOPES FILHO, Brandel José Pacheco; AZEVEDO, Kelly Andara de; MAGNI, Joana Noronha Louzada; MAZO, Janice Zarpellon. Ginástica laboral para os técnicos administrativos e em assuntos educacionais da UFRGS. Extensio: Revista eletrônica de Extensão, Florianópolis, v. 11, n. 17, p. 114-126, out. 2014. Disponível em: $<$ https://periodicos.ufsc.br/index.php/extensio/article/view/18070221.2014v11n17p114>. Acesso em: 09 mar. 2019.

MÉLLO, Ricardo Pimentel; SILVA, Alyne Alvarez; LIMA, Maria Lúcia Chaves; DI PAOLO, Angela Flexa. Construcionismo, práticas discursivas e possibilidades de pesquisa. Psicologia e Sociedade, Porto Alegre, v. 19, n. 3, p. 26-32, set./dez. 2007. Disponível em: <http://www.scielo.br/pdf/psoc/v19n3/a05v19n3.pdf>. Acesso em 1 de jun. 2018. 
MILITÃO, Angeliete Garcez. A influência da ginástica laboral para a saúde dos trabalhadores e sua relação com os profissionais que a orientam. 2001. 86f. Dissertação (Mestrado em Engenharia da Produção). Universidade Federal de Santa Catarina. Florianópolis, 2001. Disponível em: <https://repositorio.ufsc.br/handle/123456789/81438>. Acesso em: 14 fev. 2019.

MORAES, Marco Antonio Alves de; SILVA, Rosane Maria da. Quem está habilitado à prática da ginástica laboral o Fisioterapeuta e/ou Educador Físico. Revista Saúde e Meio Ambiente - RESMA, Três Lagoas, v. 2, n. 1, p. 16-24, jan. jul. 2016. Disponível em: <http://seer.ufms.br/index.php/sameamb/article/view/1563>. Acesso: 24 fev. 2019.

NAHAS, Markus Vinicius. Atividade Física, Saúde e Qualidade de Vida: Conceitos e Sugestões para um estilo de vida ativo, 6 ed. rev. e atual. Londrina: Midiograf, 2017.

NEVES NETO, Armando Ribeiro. Técnicas de respiração para a redução do stress em terapia cognitiva-comportamental. Revista Arquivos Médicos dos Hospitais e da Faculdade Ciências Médicas Santa Casa São Paulo, São Paulo, v. 56, n. 3, p. 15868 , 2011. Disponível em: <http://arquivosmedicos.fcmsantacasasp.edu.br/index.php/AMSCSP/article/view/366 >. Acesso em: 8 mar. 2019.

OLIVEIRA, João Ricardo Gabriel de. A prática da ginástica laboral, 3ํㅡㄹ ed. Rio de Janeiro: Sprint, 2006.

PIMENTA, Selma Garrido; LIMA, Maria Socorro Lucena. Estágio e docência, 6 ed, São Paulo: Cortez, 2011.

RAMOS, Glauco Nunes Souto. Preparação profissional em Educação Física: a questão dos estágios. 2002. 136f. Tese (Doutorado em Educação Física) - Faculdade de Educação Física, Universidade Estadual de Campinas, São Paulo, 2002. Disponível em: <http://repositorio.unicamp.br/jspui/handle/REPOSIP/275389> Acesso em: 28 fev. 2019. 
SANTOS, Andréia Fuentes dos; ODA, Juliano Yasuo; NUNES, Ana Paula Mori; GONÇALVES, Luciano; GARNÉS, Fabrícia Lorca dos Santos. Benefícios da ginástica laboral na prevenção dos distúrbios osteomusculares relacionados ao trabalho. Arquivos de Ciências da Saúde da Unipar, Umuarama, v. 11, n. 2, p. 99-113, maio/ago. 2007.

Disponível

em:

<http://revistas.unipar.br/index.php/saude/article/view/1520/1335>. Acesso em: 8 mar. 2019.

SERRA, Maysa Venturoso Gongora Buckeridge; PIMENTA, Lorrana Campos; QUEMELO, Paulo Roberto Veiga. Efeitos da ginástica laboral na saúde do trabalhador: uma revisão da literatura. Revista Pesquisa em Fisioterapia, Salvador, v. 4, n. 3, p. 197-205, dez, 2014. Disponível em: $<$ <ttps://www5.bahiana.edu.br/index.php/fisioterapia/article/view/436/361>. Acesso em: 8 mar. 2019.

SILVA, Sheila Aparecida Pereira dos Santos. Desenvolvimento do pensamento crítico - criativo e os estágios curriculares na área de Educação Física. Revista Brasileira de Ciência e Movimento, Brasília, v. 11, n. 3, p. 37-44, 2003. Disponível em: <https://portalrevistas.ucb.br/index.php/RBCM/article/view/508>. Acesso em: 14 fev. 2019.

SOARES, Raquel Guimarães; ASSUNÇÃO, Ada Ávila; LIMA, Francisco de Paula Antunes. A baixa adesão ao programa de ginástica laboral: buscando elementos do trabalho para entender o problema. Revista Brasileira de Saúde Ocupacional, São Paulo, v. 31, n. 114, p. 149-160, 2006. Disponível em: <http://www.scielo.br/pdf/rbso/v31n114/13.pdf>. Acesso em: 14 fev. 2019.

VASCONCELOS, Lucimara Candida. Eficácia de um programa de ginástica laboral no Hospital Evangélico de Londrina, na diminuição de absenteísmo dos colaboradores relacionados a Distúrbio Osteomusculares. 2010. 54f. Trabalho de Conclusão de Curso (Especialização) - Centro Universitário Católico Salesiano Auxilium, São $2010 . \quad$ Paulo, Disponível em: 
<http://www.unisalesiano.edu.br/biblioteca/monografias/49584.pdf>. Acesso em: 14 fev. 2019.

Enviado: Abril, 2019.

Aprovado: Setembro, 2019. 